\title{
THE CENTENNIAL OF MENDEL UNIVERSITY IN BRNO AND ITS FACULTY OF AGRISCIENCES (EDITORIAL)
}

\author{
Milada Št’astná, Antonín Vaishar ${ }^{1}$
}

Received 4 April 2019; Accepted 17 April 2019

\begin{abstract}
The paper describes the development of Mendel University in Brno and its Faculty of AgriSciences during last 100 years. It shows the present state of the University and Faculty, including facilities used for educational, scientific and other activities. The journal European Countryside owned by the University has been established 10 years ago. It is a highly cited per review periodical in the field of rural development. This special number gave the opportunity to the members of the Advisory Board to cocelebrate the anniversary by means of their own topic related scientific article.
\end{abstract}

Key words: Mendel University, Faculty of AgriSciences, European Countryside

\section{Faculty of AgriSciences of Mendel University in Brno and its activities in Rural Development}

The Faculty of AgriSciences is the direct successor of the agricultural section established in 1919 on the founding of the University of Agriculture in Brno (UOA) that facilitated the teaching of agricultural engineering (Fig. 1). Student registration took place in October 1919 at the Brno University of Technology and lectures were inaugurated on November 16, 1919 for the first 186 students. The most essential teaching items and institutes' research facilities were obtained by the mid-1920s, by which time the botanical garden, test fields and meteorological station were built. Following the closure of Czech universities at the turn of 1939 and 1940, nine Institutes, deemed beneficial for the wartime economy by the Nazis, stayed open for science and research.

The recovery of the Agricultural Institute started with the liberation in 1945 and took three years. The first meeting of UOA professors took place on May 3, 1945 and the summer term officially started on June 25, 1945. A total of 254 students enrolled, of which 168 went to the Agricultural Institute. In the 1946/1947 academic year, the agricultural section of the UOA split into two study directions - agricultural and the newly-established horticulture-viticulture direction working countrywide, which came about as a consequence of a failed attempt to establish a $3^{\text {rd }}$ (horticulture) faculty. Two-term postgraduate specialisation courses opened for Brno University of Agriculture and The Veterinary University in Brno - fisheries and hydrobiology, and animal husbandry.

At the beginning of the 1950s, there were several reorganisations due to the update on the university law and new demands for practice. The Horticulture Institute moved to Lednice

\footnotetext{
1 Prof. Dr. Ing. Milada Št’astná, ORCID: 0000-0002-4507-6207, email: milada.stastna@mendelu.cz; Assoc. prof. RNDr. Antonín Vaishar, CSc., ORCID: 0000-0003-3754-7600, email: antonin.vaishar@mendelu.cz, Mendel University in Brno, Czechia
} 
village (Southern Moravia) in 1952. Distance studies was opened for the first time in 1953/1954 to augment the education of management staff in agriculture. The Mendeleum - a centre for research in Lednice was established in 1912 and was attached to the faculty in 1965. The fodder station in Vatín and pig-keeping facility in Drásov were built. Besides these, a number of institutes had their research stations at university farms in Lednice and Žabčice and in research institutions (also called external institutes). The primary fields of study split into specialisations in the second half of the 1960s, and today's Faculty of AgriSciences building " $\mathrm{C}$ " initially started to operate as the chemistry-technology pavilion (Fig. 2).

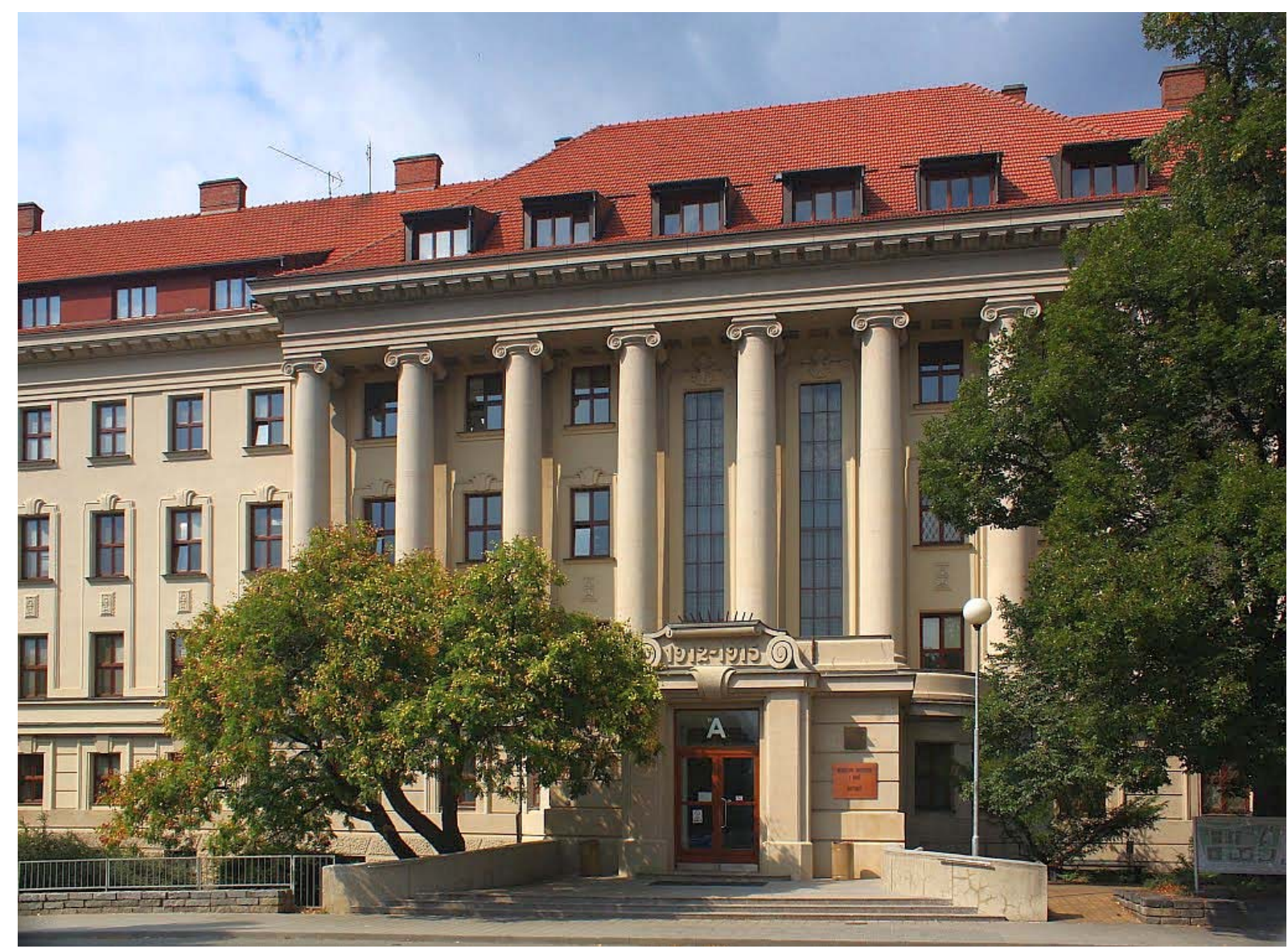

Fig 1. The oldest university building; principality of the Mendel University in Brno. Source: Archives of Mendel University in Brno

At the beginning of 1970s, faculty and institutes' management were replaced as a consequence of normalisation while specialisations were abolished. AgriSciences management suggested attaching the name of genetics founder Gregor Johann Mendel to the UOA on the occasion of the $150^{\text {th }}$ anniversary of his birth. The second half of the 1970 s brought a change of focus of research activities into primary agriculture and nutrition research.

Since 1980, all fields of study moved to a four-year duration. Building and reconstruction of permanent school farms (cow shed and poultry rearing house in Žabčice) started in 1981. In 1985, horticulture study fields were moved under the newly-established Faculty of Horticulture. The endeavour of state agricultural policy to achieve greater specialisation in agricultural production brought new interdisciplinary specialisations between 1985 and 1988.

In 1989 , the school celebrated its $70^{\text {th }}$ anniversary. Students set up a strike committee and academic Civic Forum of the UOA in association with the November events. These form the basis of two chambers (students and staff) of academic councils of the faculties and academic council of the University. In association with the socio-economic transformations after November 1989 and changes in agriculture and the food-producing industry, the Faculty kept expanding the range of fields of study to prepare graduates for better working life. 


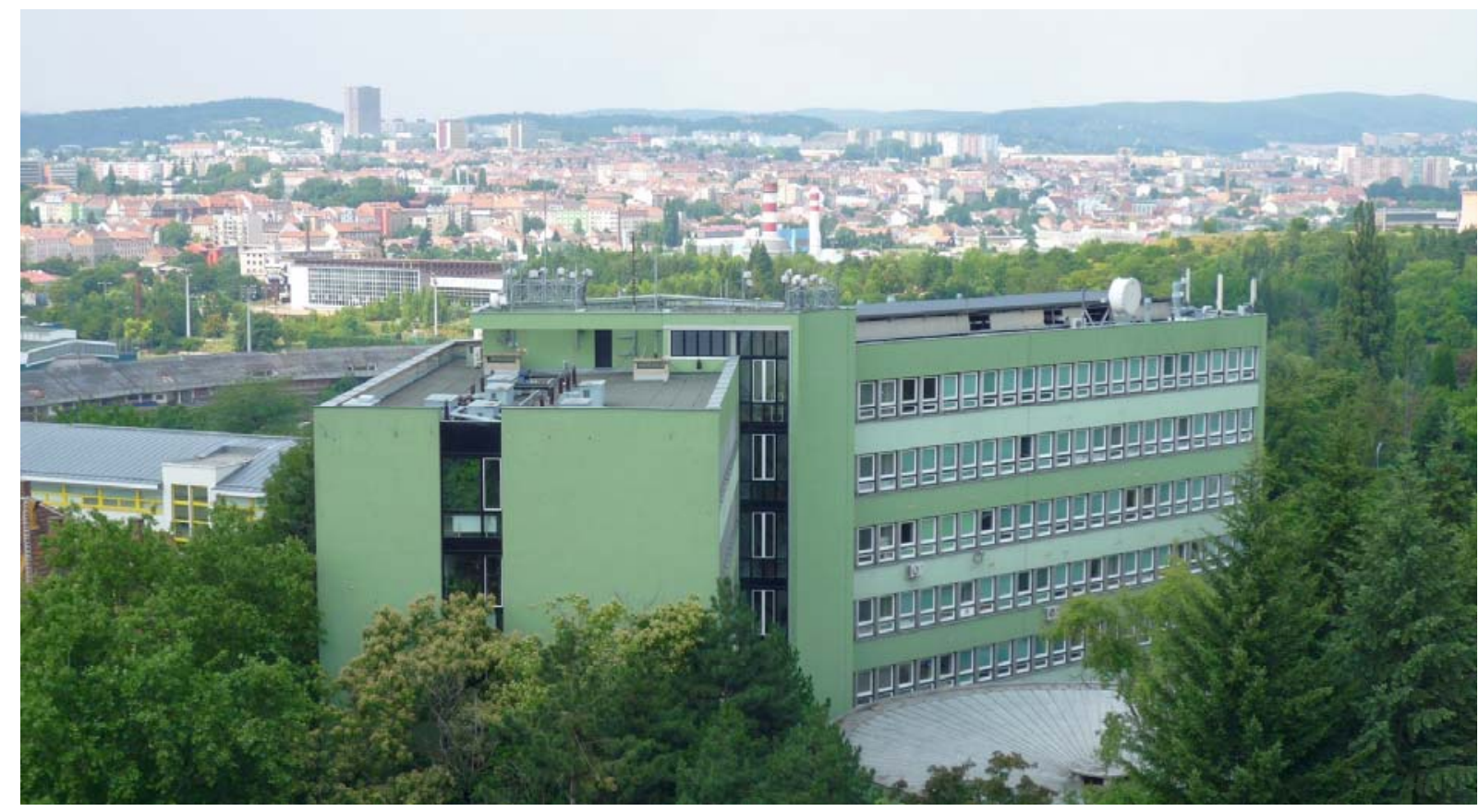

Fig 2. The headquarter of the Faculty of AgriSciences. Source: Archives of Mendel University in Brno

In 1991, Institutes transformed into Departments. UOA connected its local computer network (LAN) into the INTERNET. In 1995, the UOA was renamed as the Mendel University of Agriculture and Forestry in Brno.

ECTS - European Credit Transfer and Accumulation System was established in 2000 as a core condition of student mobilities. Students attend daily, distance and combined forms of study. In 2004 , a new building with specialised teaching premises (the $Q$ building) was opened. Between 2006 and 2010, the Faculty carried out accreditation and reaccreditation processes to bring in new and topical study programmes.

Participation of the Faculty in raising centres of excellence and large international projects is a major success. The faculty is using Žabčice University Agriculture Enterprise with its demonstration centre for plant production, completed in 2008, on site for teaching. In the same year, the scientific CEITEC MENDELU centre was established to oversee realisation of the CEITEC - Central European Institute of Technology project at the Mendel University in Brno. In 2012, the Faculty started liaising with the CzechGlobe Centre for Excellence. Similarly, there is an important involvement in international projects within H2020, COST, and other programmes. Agricultural topics of the primary research have recently expanded to include the biomedical sciences.

In 2010, the university shortened its name to "Mendel University in Brno". The Internal Grant Agency (IGA) has been serving to support and motivate students to carry out specific university research since 2011. Research results of PhD students is annually presented in the MendelNet Conference since 1994. In terms of strategy and internationalisation, the Faculty of AgriSciences has been seeking and targeting strategic partners, increasing both incoming and outgoing student mobilities and mobilities of academic staff. To support job-seeking, the AgroContact project opened at the Faculty in 2011 to be followed by the Careers Centre with field-specific portal of job opportunities. The Biotechnology pavilion was opened in 2013 (Fig. 3). 


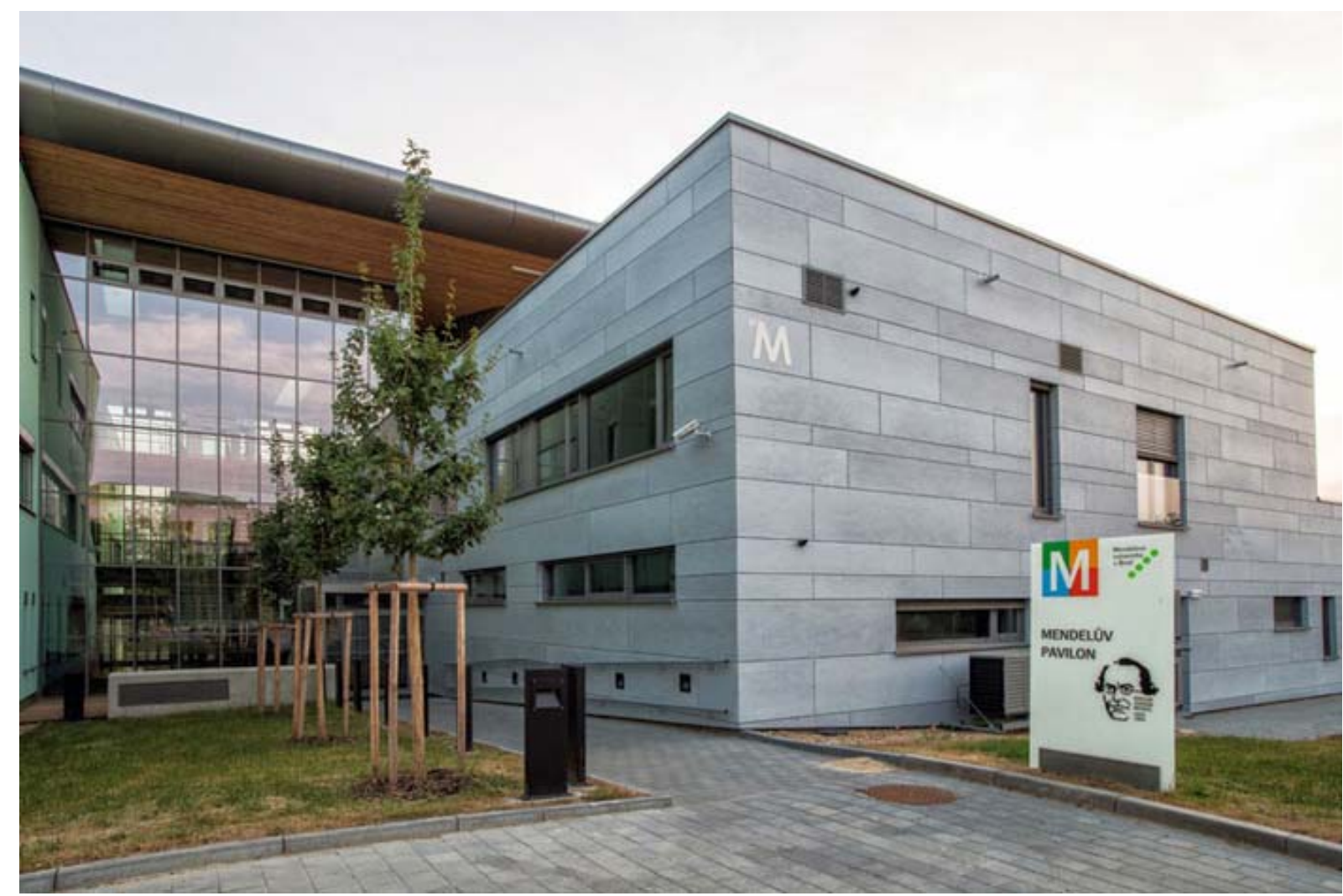

Fig 3. The modern M pavilion. Source: Archives of Mendel University in Brno

The Fellowship of the Faculty of AgriScience Graduates, Friends and Students broke off from the original Graduate Club and was registered in 2017 (abbreviated to "KLAS AF MENDELU"). The Faculty reaches out to graduates with information campaigns, participating at various events, visiting secondary schools, promotional and advertising items and products. It has lately focused on using means of mass media communication (Facebook profiles and websites) and other regular activities (MendelGrass in Vatín, MendelAgro field days, Slunečník in Žabčice, Demonstration farms - MENDEL-FARM, Coffee under the Plane Tree and others). Since autumn 2018, the Faculty Scientific Board has held its meetings in the newly-built meeting room of the Faculty of AgriSciences with a unique meeting space system.

In 2017, the Faculty of AgriSciences had 2,279 students, 311 academic workers in 14 Departments and 26 accredited degree programmes. The Faculty participates in dozens of projects of the Grant Agency of the Czech Republic, Technological Agency of the Czech Republic, projects of the Ministry of Agriculture, Ministry of Education and Sports, Ministry of Culture and other resorts among others as well as EU structural funds and international projects. At the moment, the Faculty participates in several $\mathrm{H} 2020$ projects (4 of 9 in total at the University).

The biotechnological pavilion contains a number of pilot plants, including two breweries, manufacture of baked goods, dairy products and sausages. The technical section is displayed with a certificated motor vehicle test room. The school farm Žabčice employs 110 employees, operates 2,600 ha of land and breeds ca. 1,200 of cattle. It also includes a riding club. The farm recorded the performance of about 3.7 million EUR and benefit of 400,000 EUR in 2017. The production is aimed at milk production $(47 \%)$, cattle $(17.6 \%)$, wine and vines $(17.6 \%)$, wheat $(4.8 \%)$, lucerne $(4.3 \%)$ etc. The botanical garden and arboretum were established in 1938 . It contains 4,000 orchid taxa and 4,000 wood taxa in the area of 2 ha, among others.

The Faculty of AgriSciences is a substantial part of the Mendel University in Brno (Fig. 4) which consists of five faculties (AgriSciences, Forestry and Wood Technology, Business and Economics, Horticulture, Regional Development and International Studies) and the Institute of Lifelong Learning. With 8,743 students, of it $58 \%$ women and $18 \%$ foreigners (2017), Mendel University is the $3^{\text {rd }}$ biggest in Brno. Of total number, 5,709 young people study the bachelor 
degree, 2,561 persons the master degree, and 473 the $\mathrm{PhD}$. degree ${ }^{2}$. Students are mostly from the southern part of Moravia. Many students also come from other parts of Moravia and Silesia, eastern Bohemia and Slovakia.

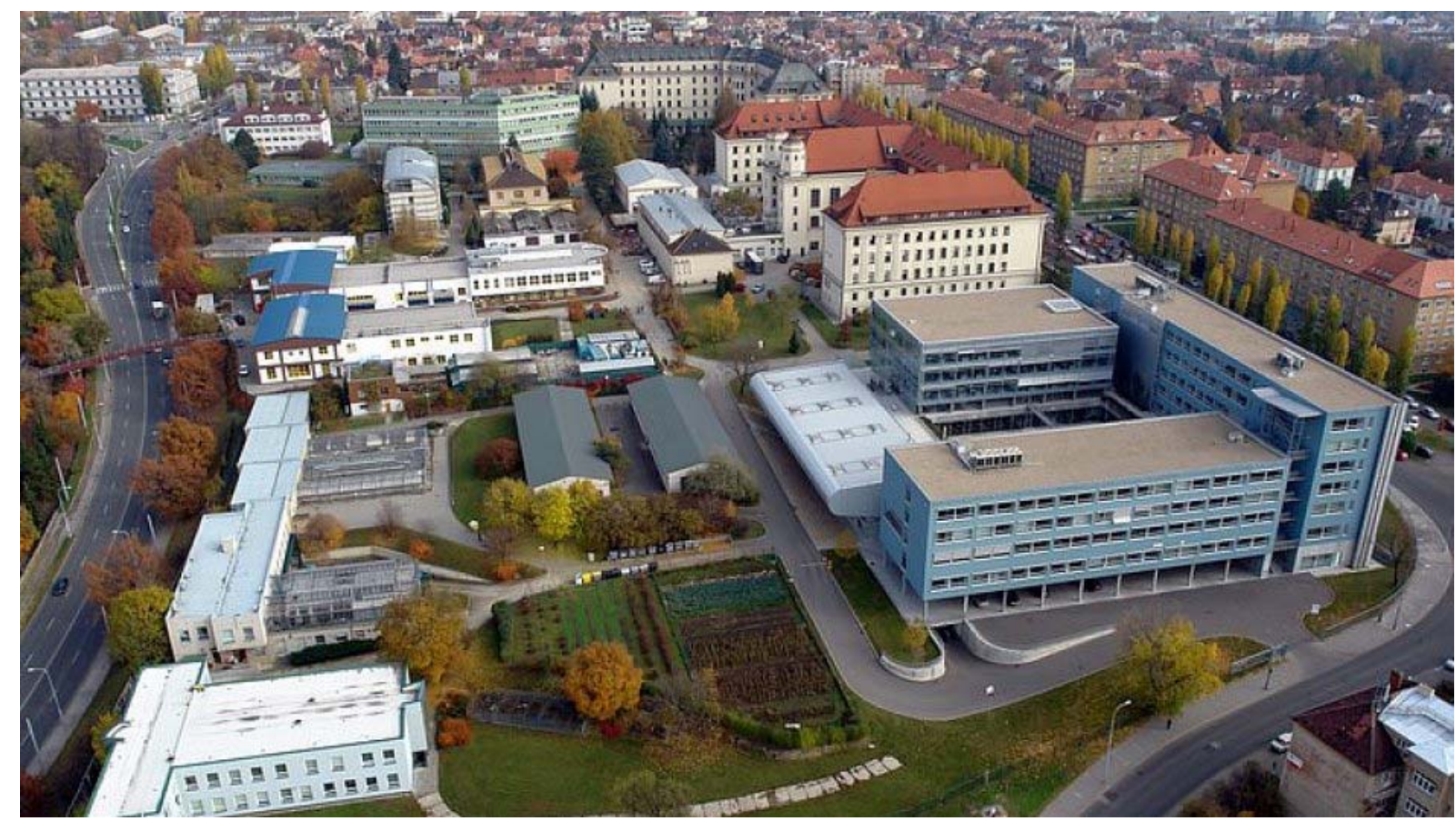

Fig 4. The main part of the campus of the Mendel University in Brno. Source: Archives of Mendel University

The library contains 433,000 physical library units. The university offers 2,842 beds in three dormitories. The kitchen cooks 3,500 meals daily which are served in six dining rooms. Chateau Krrtiny and Pond chateau Lednice provide conference facilities. The school's forestry farm Krrtiny operates 10,265 ha of forest, of which $54 \%$ is deciduous forest. The territory includes 116 forest types in 4 vegetation stages, 19 nature reserves and 2 arboretums. The company produces nearly 70,000 cubic meters of wood per year, of which 23,000 cubic meters of wood is handled in their own sawmill.

\section{The European Countryside journal celebrates 10 years}

The creation of the programme of Rural Development (of the master study) in 2007 was a reaction on the European tendencies to pay more attention to rural problems instead of solely agricultural ones. The programme follows up the bachelor study programme "Land Consolidation". The aim is to educate and prepare experts in public administration, in building up strategic plans for rural areas and in other problems concerning the countryside. It is a suitable qualification for mayors of rural municipalities.

The original impulse for founding the journal consisted in the support and visibility of the study programme "Rural Development" in the international scale. The journal has operated along with the biennial international conferences EURORURAL, where it draws papers in the sufficient international spectrum from the conference contributions and provides to its participants a possibility of a publication in the internationally recognized periodical.

European Countryside is a multi-disciplinary periodical aimed at publishing articles of all aspects of rural development in Europe. The journal prioritizes articles investigating and evaluating rural problems rather than papers aiming at individual technical or economic problems. However, we take into account that in some European countries the countryside is still strongly connected with the agriculture.

\footnotetext{
2 Annual report 2017 of Mendel University in Brno
} 
Although the Mendel University in Brno is the official owner of the journal, this role has been delegated to the Faculty of AgriSciences. Since the very beginning, the journal was conceived as an international journal. All articles are published in English. However, to support not only the unity but also the diversity of Europe, summaries can be published in languages of their authors or countries where the investigation was made.

The journal has its Advisory Board consisting exclusively of foreign experts and the Executive Board which ensures the evaluation process, technical, linguistic, financial and organizational activities. The Board of Reviewers is formed each year from the experts, who elaborate on a review. Although the journal deals with problems of the European rural areas, the spectrum of reviewers also includes experts from other continents.

We decided to produce a digital open access journal that can penetrate rapidly to all readers interested in the field. The journal does not depend on such limiting matters as the length and number of articles, number and extent of colour enclosures, time of printing and ultimately, in the price of publishing. This decision proved to be prudent because the journal is independent of the majority of "material" conditions.

A high attention has been paid to advertising information and dissemination. The journal web page has been established and it contains all the issues. It exists along with the SCIENDO web, where the articles from our journal are published. The information about each number, including links to individual papers, is directly sent to hundreds of European experts dealing with rural problems. At the present time, the list of contact addresses is continuously updated, also in relation to the GDPR rules. Recently, the journal's Facebook page has been added.

It was necessary to find a publisher able to ensure a wide international engagement of the journal. The choice fell upon a starting Polish company "VERSITA", which enabled the publishing of the adequate quality, the coverage with many databases and related services like the assignment of doi numbers or the use of anti-plagiarism software. At the same time, the international publisher has increased the prestige of the journal, especially after it was bought by De Gruyter company - one of the leading publishers of the open access literature. Recently, De Gruyter detached its division to SCIENDO, which is our present publisher.

The procedure of the evaluation of manuscripts was developed along with the increasing experiences but also with the rising number of contributions. Original personal contacts of the Executive Board members have been turned to the digital relations. Only one meeting per year was left to evaluate the previous year and to discuss necessary changes. However, each member of the Executive Board obtains each of the papers at least twice - for an initial evaluation and for the definitive acceptance. By such a way, the members have more time to individual papers. Besides it, the reporter of each paper is appointed. Their duty is to follow the manuscript through the whole evaluation process. The initial evaluation is focused on the originality of the paper, at the concordance with the aim and scope of the journal and at the basic structure and rules of a scientific paper. It results in a decision whether it is possible to shift the manuscript to the external evaluation process.

Each manuscript obtains at least two independent reviewers who should be from different countries and at least at the same professional level as the author(s). They must not be from the same university or institution as the author(s) and neither connected with them, e.g., through common publications. In addition, the reviewers are approved by the Executive Board members. The process of the selection of reviewers is the most time consuming. The average number of experts which are addressed is about 6 persons per one obtained evaluation. In some cases, it was necessary to address more than 40 experts to obtain two reviews. The reviewers who have evaluated a manuscript for European Countryside become members of the Board of Reviewers for the respective year with the right of a discount for a publishing of their own papers.

Based on the reviewers' opinions, the Executive Board (the editor-in-chief, the executive editor and the reporter as a rule) creates its standpoint with recommendations for a revision of the manuscript. The revised one is handed over the concluding evaluation to all members of the Executive Board. It is possible to reject the paper at any stage of the evaluation process. However, the Executive Board endeavours to press the authors to an improvement of their 
manuscripts rather than to reject them for no serious reasons. The protocol is created for each of the article in which all steps are recorded and all important documents are archived.

The technical elaboration and linguistic proof-reading is the final part of each of the papers. Correct citation of sources is part of the most frequent problems. Finally, it was decided to divide sources to academic ones, which are important to cross-reference (articles in journals, books, chapter in books and unpublished scientific materials as theses or research reports) and other sources (e.g., statistical and other data sources, web pages, political documents and similar sources) where the rules of the quotations are not so important. We endeavour to identify each quotation with the doi number if it exists.

The on-line form of the journal enables publishing of colour graphics up to A4 size. However, working with graphics has proven to be the most complicated phase of the technical elaboration of papers. The linguistic proofreading was originally done free of charge. With increasing number of contributions, it was not possible anymore. This was the main reason for increasing the fee for individual papers.

European Countryside publishes research articles, research notes (theoretical opinions without any empiric part), short communications (case studies covering new problems or less known regions which are not sufficiently embedded in the theory) and editorials (as an introduction to a special issue). Besides standard issues, European Countryside also published special issues. These are issues aimed at conference theme, project results or selected topics. Issues from the conferences started to be abandoned step by step because of enormous differences in quality and structure between conference presentations and research papers.

The first issue of European Countryside was published in March of 2009. The first volume consisted of papers from EURORURAL '08 conference (Fig. 5). During the first six-year period, the Executive Board was searching for an optimum style of work. In total, 24 volumes published during the first six years each contained 6.5 articles, on average. The period of 2009-2013 could be marked as the "initial period".

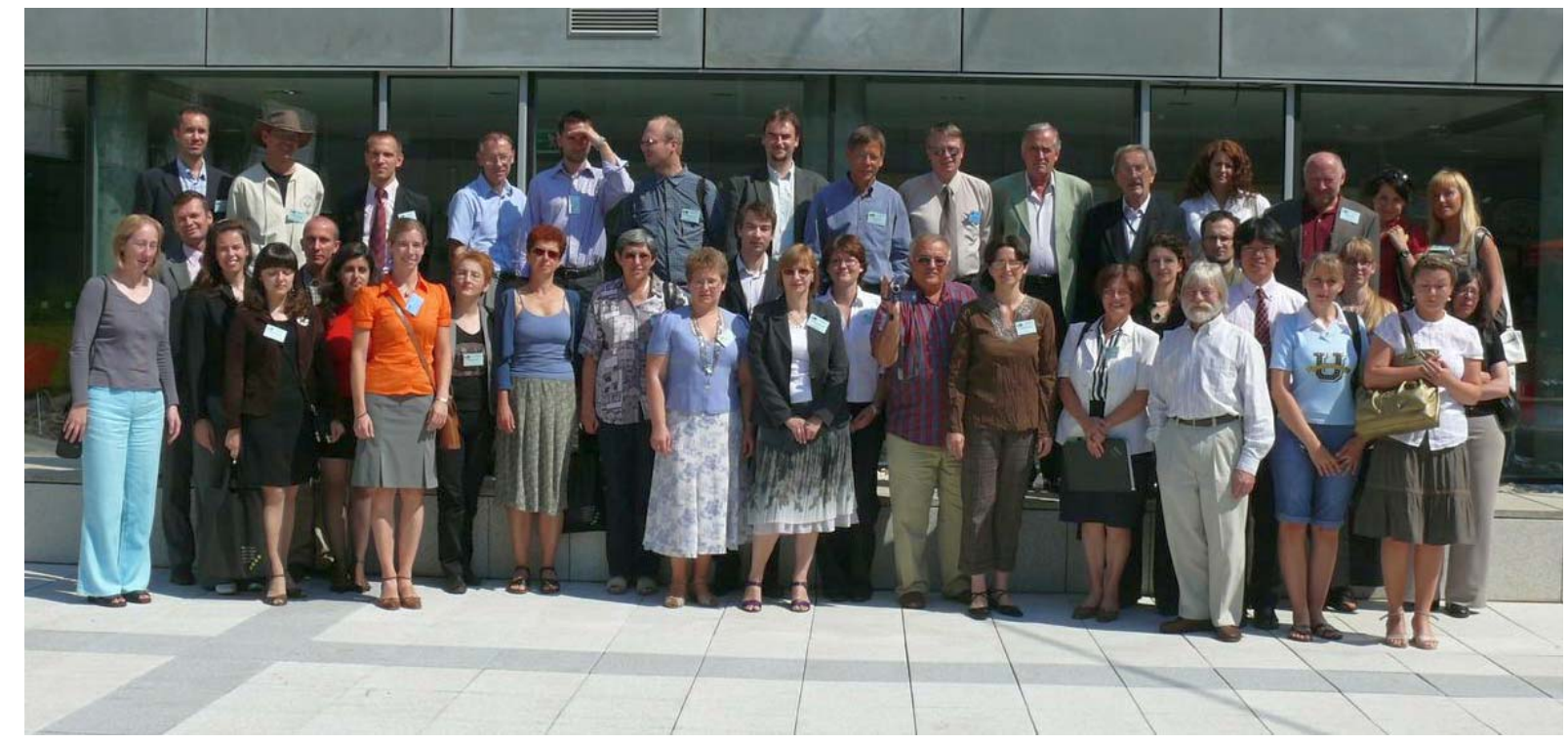

Fig 5. Participants in the first EURORURAL Conference in 2008. Photo: V. Hubačíková

The citation of articles published in European Countryside has always been considered as a key indicator. Due to the collaboration with the publisher, the journal was indexed in 56 international databases in 2013. Google Scholar, DOAJ and RePEc were the most important among them. This indexing helped to start a wide readability and also increasing citation step by step. Individual articles were downloaded more than 20 thousand times within the first 5 years. By 2014, the articles in European Countryside were cited 55-times on the Web-of-Knowledge database and 255-times on the Google Scholar. 
At the beginning of the next five-year period, the journal was included into the ERIH+ database and it later started to be covered by SCOPUS with the retroactive effect since 2012. As a result of it, the magazine was no longer dependent on the national rating, and the Czech authors gradually returned.

The second period 2014-2018 can be understood as the "stabilizing period". The average number of articles increased by 9 per issue. Such an amount of papers asked for changes in the style of work of the Executive Board, which went almost exclusively to the digital communication. The spectrum of databases where European Countryside is indexed has been widened. The journal has been indexed in Emergency Sources Citation Index of Clarivate Analytics since 2015 among others. This fact has increased the probability of reading and citation of the articles and supported the prestige of our journal.

In this period, 389 papers have been submitted, of them 244 papers have been published. They were quoted 429 times on Web-of-Knowledge database, 388 times on SCOPUS (it concerns only 193 papers since 2012) and 1,216 times on Google Scholar. The h-indexes are as follows: Webof-Knowledge 10, SCOPUS 9, Google Scholar 16 (by February 18, 2019). The Cite Score for SCOPUS is 0,78 (2017).

The coming third period should be directed to the increase of the quotation rate, especially in such databases like Clarivate Analytics and SCOPUS. It seems that the past citation growth offers a good base for it (Fig. 6).

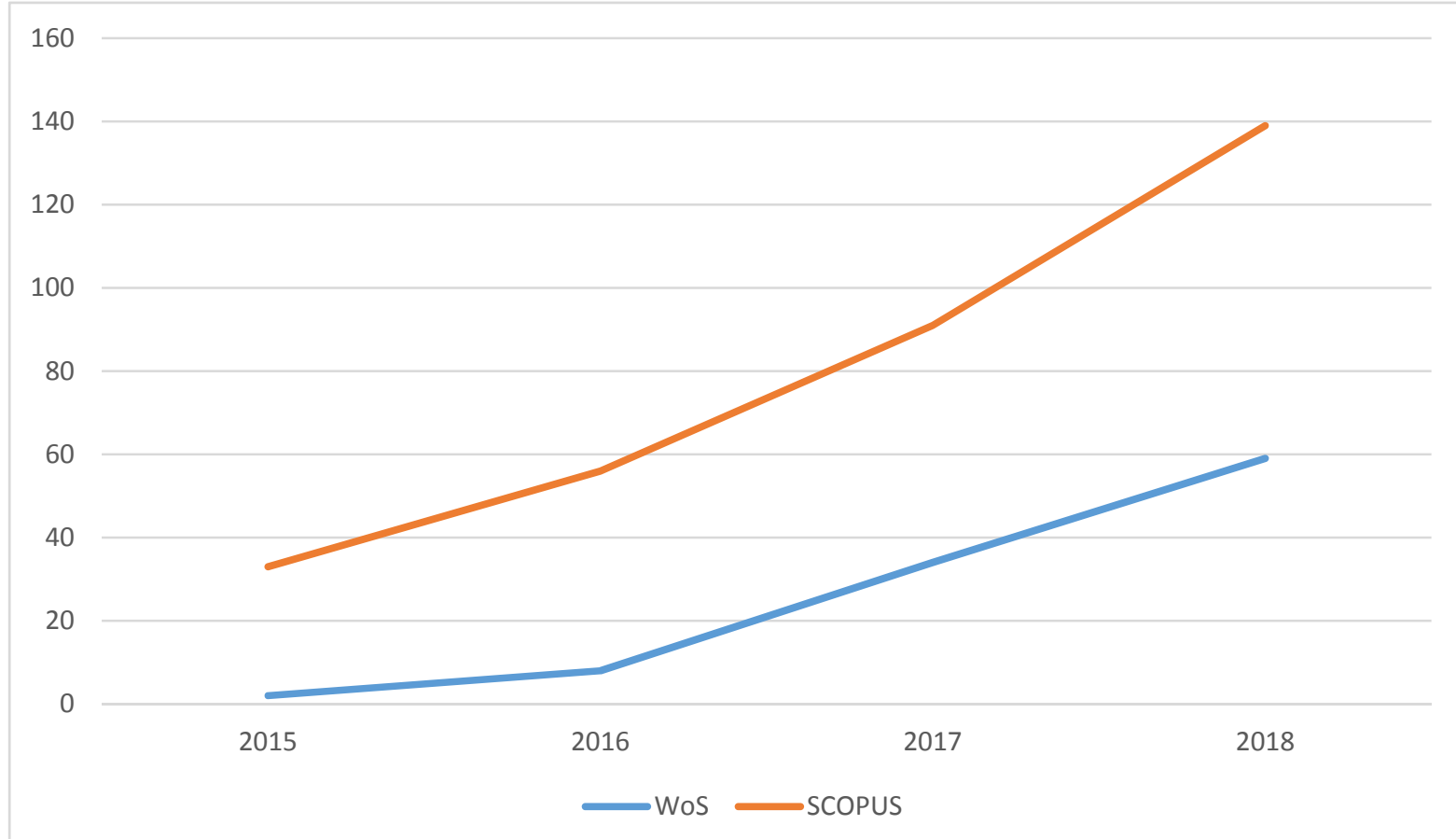

Fig 6. The development of citations of papers from European Countryside in Web-of-Knowledge and SCOPUS databases. Data: Web-of-Knowledge, SCOPUS, Own elaboration

It is important that the journal keeps regionally wide spectrum, both of authors and editors covering the whole Europe with only very rare exceptions. On the pages of the European Countryside journal, the East of Europe meets the West and the South meets the North. We have published papers from 606 authors of 33 countries. These papers were evaluated by 576 reviewers from 41 countries. Czech citizens form $24 \%$ of authors and $17 \%$ of reviewers. Not only a comparison of different parts of the countryside in Europe but also a comparison of the style of writing across Europe belongs to the main characteristics of European Countryside. 


\section{Special number to the centennial anniversary of the faculty}

The Executive Board of European Countryside decided to devote this special number to the anniversary of our Faculty and University. The possibility to submit a paper was given to the members of our Advisory Board as an appreciation of their interest and incentives. Four of them accepted this challenge. Papers of different disciplines met in the number.

Hannes Palang with his co-authors dedicates his ideas to the 100-years development of the landscape of Baltic states, its symbolic importance and its utilization for the (national) cultural identity. The problem of rural abandonment in a hilly micro-region in Ireland is illustrated by Eileen O'Rourke. Antoni Tulla is looking for value added activities able to support sustainable rural development in the case of Catalan Pyrenees. Very important problem of ensuring social services in sparsely populated area is introduced by Toivo Muilu and his colleagues who used an example of rural health services in Finland.

Let us express the gratitude to the members of the Advisory Board who supported the centennial anniversary of our Faculty with the paper for European Countryside.

\section{Acknowledgement}

European Countryside editorial board would like to thank Assoc. Prof. Pavel Ryant - dean of the Faculty of AgriSciences MENDELU for providing us with relevant materials related to the Faculty's history and development. 